\title{
MAMOGRAFIA DIGITAL: EL DESAFIO DEL PRESENTE
}

\author{
Dr. Dulia Ortega $T^{(1,2)}, T M$. Marta Taborga $V^{(2)}$, Tec. Daphne Osses $C^{(2)}$, Dra. Alejandra López $P^{(1,2)}$.
}

1. Hospital Clínico Universidad de Chile. 2. Imágenes Diagnósticas.

Abstract. Digital mammography is currently been developed as an attempt to improve image quality, and thus, increase the sensibility of the conventional system to diagnose breast cancer in early stages. This paper summarizes current technologies, advantages, and disadvantages.

Key words: Computer radiology, Digital mammography, Direct radiology, Laser, Software.

Resumen. La mamografía digital se ha desarrollado para mejorar la calidad mamográfica y así obtener un aumento de la sensibilidad en el diagnóstico de cáncer mamario en especial en estadío precoz. Este trabajo resume los tipos de mamografía digital, sus ventajas y desventajas.

Palabras claves: Láser, Mamografía digital, Radiología computada, Radiología directa.

\section{Introducción}

En mamografía la búsqueda de la excelencia, tanto en la generación de la imagen, como en el almacenamiento y comunicación de los resultados, ha conducido su desarrollo hacia la digitalización.

Esto fue generado en 1991, posterior a un panel del National Cancer Institute en USA, donde los expertos en mamografía determinaron hacia donde deberían dirigirse los fondos para el desarrollo e investigación ${ }^{(1)}$.

Grandes avances se han realizado a través de dos líneas. La primera, es la Mamografía Digital propiamente tal $\left.\right|^{(2,3)}$, conocida en la literatura con la sigla DR, éstos mamógrafos usan ya sea un método indirecto, con dos pasos para la digitalización o bien

Ortega D. y cols. Mamografía digital: El desafío del presente. Rev Chil Radiol 2004; 10: 35-37.

Correspondencia: Dra. Dulia Ortega T.

Servicio de Radiología, Hospital Clínico Universidad de Chile. Santos Dumont 999. Independencia. Santiago de Chile.

E-mail:dortega@ns.hospital.uchile.cl un sistema directo, en donde los equipos con sus detectores, convierten directamente sus lecturas en carga eléctrica (Figura 1).

Una segunda línea es la entregada por la radiología computada (CR), que usando un lector láser, procesa la placa obtenida en un mamógrafo convencional.

\section{Mamografía convencional}

En la mamografía convencional la imagen se obtiene usando detectores pantalla-película, que graban los fotones de radiación que pasan a través de la mama (Figura 1). Uno de los protagonistas, en esta imagen analógica son los detectores pantallapelícula, que en la práctica determinan en alto grado entre otras cosas, la resolución espacial.

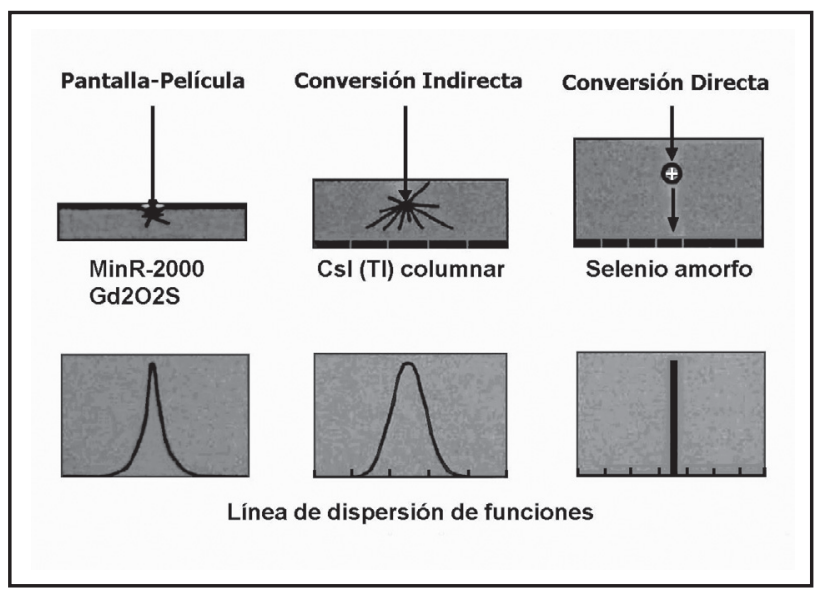

Figura 1 a-c. Comparación entre los sistemas detector pantalla-película y DR. a: Sistema pantalla-película. En este la radiación no atenuada contacta con los cristales, se generan fotones de luz que impresionan la película. b: Sistema digital con conversión indirecta. Este sistema utiliza una capa centellante que absorbe los rayos $X$, genera fotones de luz, y estos son detectados por fotodiodos. c: Sistema digital con conversión directa. Utiliza un fotoconductor para absorber los rayos $X$ y directamente genera la señal. 
Algunas pantallas con más actividad que otras, tendrán más material fosforescente que al interactuar con los fotones de radiación permitirán una exposición más corta disminuyendo la posibilidad de borrosidad por movimiento y además reducirán la dosis glandular, sin embargo, la calidad se verá afectada por el aumento de la borrosidad resultante de la producción e interacción de una mayor cantidad de luz ${ }^{(2)}$.

Un problema importante del sistema detector pantalla-película es el hecho que las películas no tienen capacidad de respuesta inmediata a los fotones que la inciden, es así como obtenemos en las áreas de mayor densidad, mayor absorción de radiación, que en la imagen aparecen más blancas ${ }^{(2)}$, quedando un rango muy pequeño para que la atenuación de la radiación en los tejidos se exprese en términos de contraste (Figura 2). Este hecho debe tomarse en cuenta sobre todo cuando constatamos que aunque con la película se obtenga una alta resolución, al no acompañarse de un adecuado contraste, determinara que algunas lesiones sean subdiagnosticadas.

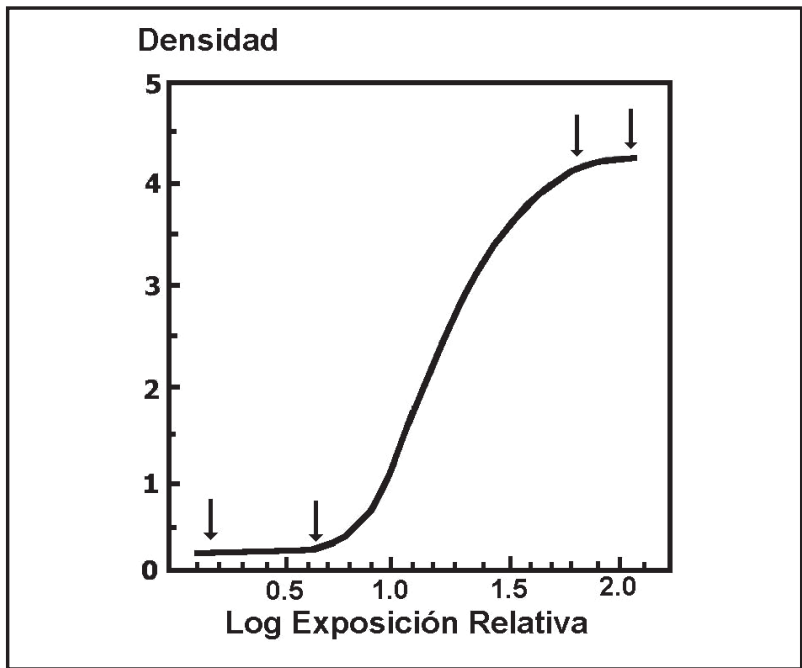

Figura 2. Curva de Hunter y Driffield. En ambos extremos (pie y hombro) de la curva (flechas) no se producen contraste, el cual solo ocurre en el espacio de la pendiente (modificada de referencia 2).

Por último en el sistema pantalla-película la imagen una vez obtenida no puede modificarse, puede perderse y en ocasiones su transmisión y almacenamiento crea verdaderos problemas. Sin embargo, debemos tener en consideración que este sistema, es económico y eficaz en la producción de imágenes cuando se usa una adecuada combinación pantalla-película. La película usada normalmente tiene una resolución teórica de 17 a 20 pares de líneas por $\mathrm{mm}^{(2)}$.

\section{Mamografía digital}

Todas las razones enunciadas llevaron a establecer como prioridad la línea de investigación hacia la mamografía digital, desarrollándose altas tecnologías que presentan diferencias importantes en su desarrollo.

Se ha logrado dos tipos de obtención de imágenes conocidas como digitales ${ }^{(2,3)}$. Ambos van asociadas al desarrollo de otros factores, diferentes de la producción de la imagen propiamente tal, como lo son la tecnología de monitores, vías de transmisión, software de procesamiento de las imágenes, etc.

La mamografía digital primaria o digital propiamente tal(2) mide directamente los fotones de radiación que pasan por la mama. La importancia de esto es que el equipo tiene la capacidad de leer los primeros fotones lo cual no es obtenido con el sistema pantalla-película y además lee un gran flujo de ellos, permitiendo la obtención de información de una enorme cantidad de puntos de la mama, practicándose un mapeo más exacto de las variaciones de atenuación de los tejidos mamarios.

Este sistema se utiliza en mamógrafos digitales directos y mamógrafos digitales indirectos.

Los mamógrafos digitales directos tienen detectores de radiación que convierten directamente la información en carga eléctrica (Figura 3). Habitualmente utilizan selenio como fotodetectores por su afinidad con los rayos X. Los indirectos ocupan dos pasos en el proceso de digitalización: la radiación convertida en luz es recibida por fotodiodos y transformada en carga eléctrica.

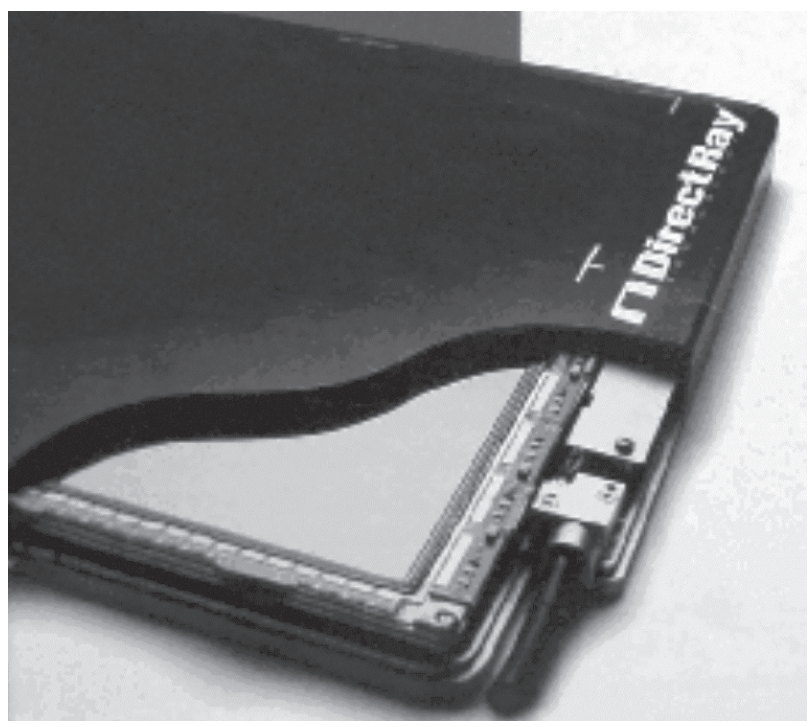

Figura 3. Corte de detector digital directo. Este usa Selenio amorfo. 
Ambos sistemas pertenecen al grupo conocido en la literatura como radiología digital directa (DR).

El segundo sistema aún no aprobado en USA por la Food and Drug Administration (FDA) es la conocida como sistemas de radiología computada (CR) dado que utiliza procesos computacionales y digitaliza posteriormente la imagen ocupada con un lector láser.

Los digitalizadores trabajan al pasar la luz a través de la radiografía, grabando la intensidad de la luz transmitida en cada punto de la imagen, consignándole un número a esta intensidad lumínica. Luego se copia de manera digital, permitiendo manipulación posterior de la imagen. La crítica a este sistema tiene que ver con que sería una copia de la imagen latente que potencialmente pierde información y aumenta el ruido en la imagen.

\section{Discusión}

La mamografía digital tiene dos expresiones: CR y DR. Los CR son la digitalización de la imagen convencional. Los DR son mamógrafos digitales propiamente tales. De estos hay dos tipos, que básicamente se diferencia en que uno es más directo que el otro, al evitar el paso intermedio de luminosidad.

En el campo de la digitalización de imágenes, los factores de calidad se ven influidos por múltiples protagonistas.

La mamografía digital no esta ajena a este hecho aunque siguen teniendo importancia los factores de calidad convencionales. Aparte de la fuente de digitalización, los factores principales son las estaciones de trabajo, la luminosidad de las pantallas, las líneas del monitor, los softwars de manipulación, la velocidad de transmisión, que sin lugar a dudas son objeto de mejoras sustanciales tanto en mamografía digital (DR) como en imágenes digitalizadas (CR).
En el análisis clínico, los trabajos de investigación recientes han demostrado que la mamografía digital al menos es tan buena como la convencional en el diagnóstico por imágenes ${ }^{(5)}$, aclarando que aún no se reconocen resultados del método más directo de todos que ya está en el mercado.

Es un tema que debemos seguir analizando, porque creemos aún necesita mayor desarrollo.

\section{Conclusiones}

Aún en proceso de evolución estos sistemas son prometedores. El sistema de digitalización de la imagen (CR) representa una veta a investigar, por tratarse de un método asequible en términos de costos para nuestro medio.

De todos modos es imperativo comprender que tanto por razones de potencial calidad como por factores de avance de la radiología general la mamografía va a ser digital tarde o temprano, esto va a facilitar el funcionamiento del servicio de radiología, va a evitar las recitaciones de pacientes, va a mejorar la información a los tratantes y va a apoyar la descontaminación por la eliminación de los químicos y placas radiológicas.

\section{Bibliografía}

1. Shtern F. Digital mammography and related technologies: a perspective from the national cancer institute. Radiology 1992; 183: 629-630.

2. Kopans D.B. Breast Imaging. Lippincott Raven, Philadelphia. 2nd ed., 1998; Paginas 816-829.

3. GE Senographe 2000D FDA 1999.

4. Vendantham S, et al. Full Breast digital mammography with an amorphous silicon-based flat panel detector: physical characteristics of a clinical prototype. Medical Phiysics, 2000; 27: 558-567.

5. Skaane P, Young K, Skjennald A. Population-based mammography screening: Comparison of screen-film and full-field digital mammography with soft-copy reading Oslo I study. Radiology 2003; 229: 877-884. 